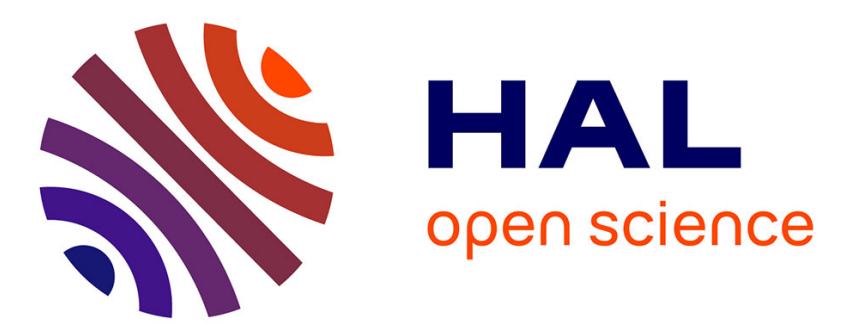

\title{
Evaluation of performance improvement by model predictive control in a renewable energy system with hydrogen storage
}

David Morin, Yoann Stevenin, Cedric Grolleau, Pascal Brault

\section{To cite this version:}

David Morin, Yoann Stevenin, Cedric Grolleau, Pascal Brault. Evaluation of performance improvement by model predictive control in a renewable energy system with hydrogen storage. International Journal of Hydrogen Energy, 2018, 43 (45), pp.21017 - 21029. 10.1016/j.ijhydene.2018.09.118 . hal01912089

\section{HAL Id: hal-01912089 \\ https://hal.science/hal-01912089}

Submitted on 5 Nov 2018

HAL is a multi-disciplinary open access archive for the deposit and dissemination of scientific research documents, whether they are published or not. The documents may come from teaching and research institutions in France or abroad, or from public or private research centers.
L'archive ouverte pluridisciplinaire HAL, est destinée au dépôt et à la diffusion de documents scientifiques de niveau recherche, publiés ou non, émanant des établissements d'enseignement et de recherche français ou étrangers, des laboratoires publics ou privés. 


\title{
Evaluation of performance improvement by model predictive control in a renewable energy system with hydrogen storage
}

\author{
David Morin ${ }^{1}$, Yoann Stevenin ${ }^{1}$, Cédric Grolleau², Pascal Brault ${ }^{2 *}$ \\ ${ }^{1}$ SA Powidian, 20 Rue Marie de Lorraine, ZAC des Fougerolles, 37700 La Ville-aux-Dames \\ ${ }^{2}$ GREMI, CNRS - Université d'Orléans, BP6744, 5067 ORLEANS Cedex 2, France \\ *Corresponding author: pascal.brault@univ-orleans.fr
}

\section{Abstract}

Nowadays islanded microgrids mostly rely on diesel generator. In order to reduce greenhouse emissions, two islanded microgrids with hydrogen storage have been installed and are currently working autonomously in Reunion Island and France. Energy management implemented on these stations fall in the myopic control category. This study aims to determine the performance improvement that could be achieve on such stations using model predictive control. Ability to supply to the loads and energy losses minimisation are our main objectives. Lifetime degradation is also taken in consideration. Simulations shows that significant improvement can be brought, with a $76 \%$ decrease of the station's defaults time and better fill rate of hydrogen tank and batteries. In the meantime, chemical and electrical losses are reduced by 38 and 11\%, and the batteries degradations are decreased by around $1 \%$. The relevance of taking into account the electrolyser and fuel cell degradations depends on the time-step of the control. These results give a performance target in order to implement a real-time model predictive control in the microgrids, and eventually can be used to better sizing of future microgrids with similar architecture.

\section{Introduction}

The last decade witnessed significant improvement in the understanding by the public at large of the impacts that can be caused by climate change. This increasing awareness leads in turn to more policies and actions to counterbalance global warming and to adapt ourselves to its effects. The energy sector is no exception to the general trend.

Besides the major task of efficiently producing energy for a growing energy demand while reducing greenhouse gas global emissions, powering off-grids areas is also a great challenge. Indeed, numerous of these sites still have a diesel generator as principal or secondary power source and thus rely on oil. The expansion of renewable energy production is a promising way to overcome this fossil energy issue. However, renewable energies like photovoltaics and/or wind energies need an energy storage system, due to random and irregular power production. In this article, we study the Energy Management Strategy (EMS) of a Renewable Energy System (RES) in remote areas. The simulated RES has no diesel generator but includes a hybrid energy storage system composed of batteries and an hydrogen chain. Such a RES has been installed by company Powidian in the Parc de la Vanoise (France) and in the Cirque de Mafate (Reunion Island). Today the EMS of both stations are based on a myopic strategy. Our goal is to quantify the potential gain that could be achieved by implementing a Model Predictive Control 
(MPC). MPC has been widely in industry in general. In the context of RES, it consists of predicting the energy production and consumption on a defined temporal horizon and to determine the optimal control regarding these predictions and a behaviour model of the station. Examples of implementation for RES with hydrogen storage can be found in [1-8]. In [1] Valverde et al developed a MPC to ensure the energy management to follow several goals, including the protection of the components (batteries, fuel cell and electrolyser), and to pilot the components to a predefined operating point. The control has been experimentally tested using a labscale microgid (HyLab) in the University of Sevilla[9].The command has been developed to control the RES for very short term temporal horizon (10 seconds) and has been combined with a short term temporal horizon (4 days) control developed by Cau [2], using also a model predictive control. The objectives of Cau's MPC is to minimize the operating and maintenance cost over the whole lifetime of the RES. The labscale HyLab has also been used by Salazar in order to validate another MPC control. Objectives of the control were to supply the loads, to minimise the operational costs while assuring a good durability of key components. To do so, she introduced 4 continuous duration variables in such way that the problem is formulated as a nonlinear problem with continuous variables, easier to solve than Mixed Integer Linear Problems.[10,11]Another MPC has also been developed by Serna et al in [3]. In this study, the goal was to ensure the hydrogen production from wind and waves turbines and to preserve the state of health of the electrolyser. To do so, he developed a Mixed Integer Quadratic Programming resolution of MPC with naïve predictions. In [4] Konstantinopoulos et al presents a predictive control to balance the intermittency of renewable production while minimizing the financial cost. They assumed they know the probability density functions of forecasting errors and resolve the optimization problem with a Harmony Search Algorithm. Bornapour et al consider the problem of optimal scheduling for a RES in a stochastic programming framework. The RES is composed of PV panels, wind turbines, thermal units and a fuel cell. Its goal is also to maximise the financial revenue over the station's lifetime. The problem is resolved through the Modified Fireflies Algorithm in a first paper in [5], which is an evolutionary algorithm, and a Teaching-Learning Based Optimisation Algorithm in a second one in [12]. Torreglosa et al implemented a predictive control of a RES with hydrogen storage and compared the performance improvements compared to a myopic strategy [6]. The goal was to meet the demand while assuring that batteries state of charges and hydrogen tank level stays between some reference value. MPC also increased the fuel cell and electrolyser efficiency by determining an optimal operating point for these components. However, lifetime considerations are not addressed. Two low-level MPC were introduced by Trifkovic et al to control the fuel cell and the electrolyser while the high level control was assured by a myopic strategy [7]. Increasing efficiency and renewable energies penetration while meeting the demand were the target. The energy storage system contains no batteries and rely only on hydrogen storage. Here again, ageing is not addressed. Finally, Nease \& Adams implemented a predictive control with rolling horizon for a RES with a Solid Oxyde Fuel Cell and Compressed Air Energy Storage [8]. Use of stochastic Monte-Carlo simulations are used to deal with the uncertainty associated with forecasts. An economic objective is targeted and a trade off with load following performance is introduced.

All of these papers show feasibility of controlling RES with hydrogen storage by a model predictive control. When comparison with other types of control are available, it appears that MPC improves performances of the RES $[2,6,13]$. This result can also be widely found for RES without hydrogen storage (see for example [14-17]). However, for a large majority of the above studies, the main objective of such command is to minimise the financial cost (or maximise the revenue) over the RES lifetime while ensuring power availability. While aiming for a better profitability for such expensive technologies is understandable, we think such questioning is not the only major issue to be solved. The industrialisation phase of the hydrogen storage system components - fuel cells, electrolysers and hydrogen storage - while needing improvements, is expected to be significant in the future [18]. 
Therefore, the discount rates and cash flows relative to these components in near future are highly unpredictable and could lead to significant deviations when considered too early. For this reason, we choose to optimize the efficiency of the RES by minimizing energetic losses during the power conversions while assuring the load to be met. As these are physical process, the results presented here will stay valid no matter of the market evolution. In addition, the duty factor of the fuel cell and electrolyser is expected to be reduced by the use of a predictive control, leading to a reduction of their performances [13]. Therefore, the health of batteries, electrolysers and fuel cells are also considered in the optimisation process. To our knowledge, there are no such study applied for RES with hydrogen storage and similar architecture and for the same objectives taken altogether.

The main contributions of this papers are:

- Describing the model used in the study that will be reused in future works.

- Optimising the energy management to minimize default time, energetic losses and ageing process altogether through a multi-objectives formulation.

- Quantifying the performance improvement brought by implementing a MPC regarding the objectives mentioned above.

Section 2 of this paper presents an overview of the architecture of the stations. Section 3 deals with the model of each component. Section 4 exposes the current EMS, the principle of MPC and defines its objectives functions. Results and discussion are presented in section 5.

\section{Architecture of the station}

In remote and/or off-grid area, electricity is not provided by the grid and thus it must be produced onsite. Nowadays, a wide majority of such power production is assured by diesel generators, resulting in a high dependence of imported fuel and $\mathrm{CO}_{2}$ emissions. Renewable energy production like solar photovoltaic or wind turbine can overcome these issues. These technologies, however, cannot be controlled by an operator and depend on stochastic parameters such as wind speed and daylight. RES thus relies on storage systems to achieve full autonomy. If a large variety of storage technologies can be used, the present study focuses on a hybrid batteries / hydrogen energy storage system. A diagram of the such RES is provided in Figure 1.

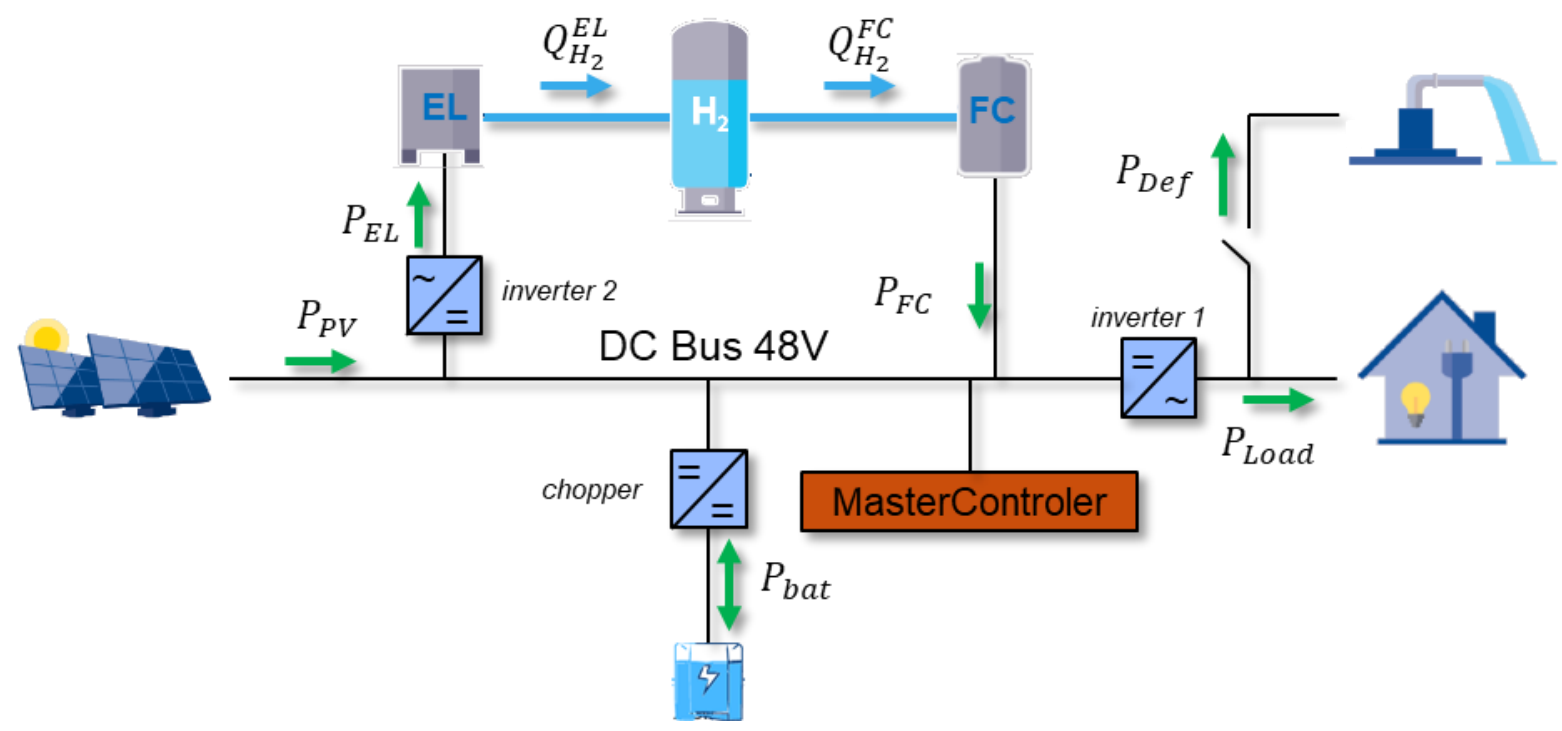


It can be decomposed in four parts:

1) The power production subsystem, composed of two branches of five solar panels plugged in series. We suppose that they all work at their Maximum Power Point in all time.

2) The loads - both deferrable and not deferrable - connected to an inverter to provide a AC power.

3) A short-term Energy Storage Subsystem (ESS), composed of Li-ion batteries.

4) A long-term ESS, composed of an electrolyser, a fuel cell and a hydrogen tank.

Every component is connected on a $48 \mathrm{~V}$ DC bus through converters. A central controller, called MasterControler, is responsible for collecting data from each component and for their control. A 4G modem is integrated so the RES can be remotely supervised and updated. As converting electricity to hydrogen and again to electricity is low-efficiency process, usage of lithium-ion batteries is intuitively preferred over the hydrogen subsystem.

\section{Models}

The behaviour of each components of the studied RES is provided in the following sections. The timestep used in further simulations is greater by several orders of magnitude than typical constant time associated with component's fast dynamics. Consequently, fast dynamics are not taken into account.

\subsection{Photovoltaic panels}

The theoretical power that can be delivered by the PV panels (after MPPT converters) is noted $P_{P v}^{\text {theo }}$ and is given by $[19,20]$ :

$$
P_{P V}^{\text {theo }}(t)=N_{p} \times \eta_{M P P T} \times P_{\text {branch }}(t)
$$

With $\eta_{M P P T}$ being the MPPT converter efficiency and $N_{p}$ the number of parallel branches. The power $P_{\text {branch }}$ delivered by one series of panels is calculated by (2)(12).

$$
P_{\text {branche }}(t)=N_{s} \times \max \left(P_{c} \times \frac{E(t)}{E^{0}}\left(1-\frac{\gamma}{100}\left(T_{\text {cell }}(t)-T_{\text {cell }}^{0}\right)\right), P_{M P P T}^{\max }\right)
$$

$N_{S}$ is the number of PV panels in one series, $P_{c}$ is peak power of one panel, $\gamma$ the thermal coefficient, $P_{M P P T}^{\max }$ the maximal power delivered by MPPT converters, $E$ the incidence irradiance, $T_{\text {cell }}$ the temperature at the cell surface. $E^{0}$ and $T_{\text {cell }}^{0}$ are the incident irradiance and the cell temperature under standard conditions.

\subsection{Batteries}

We suppose that power flows are equally distributed over the batteries. We can hence consider the battery bank as a unique battery, modelled by its instantaneous power, its state of charge and state of health. We compute the state of charge at each time step with (3)

$$
\operatorname{SOC}_{b a t}(t+1)=S O C_{b a t}(t)+\Delta t \frac{\sqrt{\eta_{b a t}} P_{b a t}^{+}+P_{b a t}^{-} / \sqrt{\eta_{b a t}}}{V_{\text {nom }} \times C_{\text {nom }}}
$$


$\Delta t$ is the time step, $\eta_{b a t}$ the battery round trip efficiency, $V_{\text {nom }}$ the nominal voltage, $C_{\text {nom }}$ the nominal capacity. $P_{b a t}^{+}$and $P_{b a t}^{-}$are the power charged and discharged between time $t$ and time $t+1$. The state of health gives an overview of the capacity loss due to ageing process. For a state of health equal to 1 for a new battery and to 0 when its nominal capacity is only $80 \%$ of its initial capacity, it is defined by

$$
\mathrm{SOH}_{\text {bat }}(t)=5 \frac{C_{\text {nom }}(t)}{C_{\text {nom }}^{0}}-4
$$

When $\mathrm{SOH}=0$, the battery is considered unusable and must be replaced [21]. The capacity degradation is calculated through an empirical model developed by Wang et al [22,23]. It can be decomposed by the sum of calendar ageing $A_{c a l}$ and cycling ageing $A_{c y c}$. The calendar ageing depicts the natural capacity loss through time. The cycling ageing accounts for the degradation due to repetitive charges and discharges.

$$
\begin{gathered}
A_{c y c}(t)=\left(w_{1} T_{\text {ext }}^{2}+w_{2} T_{\text {ext }}+w_{3}\right) e^{\left(w_{4} T_{\text {ext }}+w_{5}\right) \times C_{I}} \text { dec } \times E_{\text {tot }} \\
A_{\text {cal }}(t)=w_{6} e^{-\frac{E_{A}}{R T_{\text {ext }}} \sqrt{t}} \\
\frac{C_{\text {nom }}(t)}{C_{\text {nom }}^{0}}=1-\left(A_{\text {cyc }}(t)+A_{\text {cal }}(t)\right)
\end{gathered}
$$

$T_{\text {ext }}$ is the ambient temperature, $C_{I_{d e c}}$ is the rated capacity for a discharge current $I_{d e c}, E_{\text {tot }}$ the total amount of energy discharged by the battery during its lifetime, $E_{A}$ the activation energy, $R$ the gas constant and $w_{i}$ empirical parameters. Other influence of ageing on internal impedance is not considered here. It is reasonable since a rise of the internal impedance mainly have two consequences. First, their maximal power decrease both for charges and discharge. However, batteries rarely reach their maximal power in our application so we can neglect this effect. And second, the temperature inside the batteries increases due to higher joule effect, but this consideration is beyond the scope of our study.

\subsection{Fuel cell}

A proton exchange membrane fuel cell (PEMFC) is an electrochemical device which aim is to produce electricity from hydrogen. It is composed of numerous cells connected in series and parallel. A stream of gaseous hydrogen is brought to the anode part where it will be decomposed in two protons. Then, the protons migrate to the cathode part through the polymer-made membrane and react with dioxygen to produce pure water. The electrons produced while decomposing the dihydrogen are collected to generate electrical power. We suppose that the fuel cell always works at its nominal power when active:

$$
P_{F C}= \begin{cases}P_{\text {nom }}^{F C} & \text { when active } \\ 0 & \text { otherwise }\end{cases}
$$

This simple model is not often used in the literature. Authors usually prefer more complex models based on polarization curves and internal voltage losses (see for example [24]). The choice of using this model is guided by the fact that the classical models only consider the process within the cells and the stacks. Fuel cells, however, also contain auxiliaries like pumps or electronics for which consumption are not known. Moreover, supplier can introduce their own strategies to manage the flow of reactants and to maintain the cells in good operating conditions. These strategies are also not known and depend 
on the supplier. For this reason, we suppose the fuel cell to be locally controlled at nominal conditions given by the supplier. Doing so, we are taking into account all the reactant losses and re-use, as well as auxiliaries consumption.

The amount of hydrogen consumed in the process given by the supplier' datasheet is $32 \mathrm{slpm}$ at nominal power. It considers the efficiency and hydrogen lost during the process (purges). We suppose this quantity constant through fuel cell the lifetime.

We also define a state of health for the fuel cell $S O H_{F C}$ that depicts the performance loss which ageing. Just like the batteries, the $S O H_{F C}$ is equal to 1 for a new fuel cell and get to 0 at the fuel cell end-oflife (EOL). The EOL defined as the moment when the nominal power delivered by the fuel cell is $90 \%$ of its initial power.

$$
S O H_{F C}=10 \frac{P_{n o m}^{F C}(t)}{P_{n o m}^{F C, 0}}-9
$$

The nominal power decrease through the loss of nominal voltage that occurs at each start, each stop and for each time step when the fuel cell is active. We assume a loss of $106 \mu \mathrm{V}$ per stop or start and a loss of $10 \mu \mathrm{V}$ for time step of fuel cell usage [25].

\subsection{Electrolyser}

An anion exchange membrane electrolyser is also an electrochemical device but which role is the exact opposite of a fuel cell i.e. to produce hydrogen from water and electrical power. Pure water is brought to the anode and is reduce to hydrogen $\mathrm{H}_{2}$ and anions $\mathrm{OH}^{-}$. The anions then migrate at the cathode through the membrane and there produce water and oxygen. We presume the electrolyser always works at its nominal power when active. We also presume that the quantity of produced hydrogen (8.3slpm at nominal power) is constant through the electrolyser lifetime and is given by the supplier. Its state of health $S O C_{E L}$ describe the rise of electrical power consumed for a given quantity of hydrogen. The electrolyser reaches its EOL when nominal power increase exceeds $110 \%$ of its initial nominal power. At that time, $S O C_{E l}=0$.

$$
S O H_{E L}(t)=11-10 \frac{P_{\text {nom }}^{E L}(t)}{P_{\text {nom }}^{E L, 0}}
$$

By analogy with the fuel cell degradation, we consider a $106 \mu \mathrm{V}$ rise per start or stop and $10 \mu \mathrm{V}$ per time step of electrolyser usage.

\subsection{Loads}

The RES contains both controllable and not controllable loads. The first can be control by the EMS and are often associated with comfort while the last are critical and endured. Controllable loads considered here are classified in time-shiftable and power shiftable loads. Both can be interruptible or not.

\subsubsection{Time shiftable loads}

Time shiftable loads are loads whose moments of activation are controllable by the EMS. This class is suitable for tasks whose consumption profile is finite and known (e.g. a washing machine, charge of an electrical car, etc...). When the user wants such task to be done, he specifies to the EMS the admissible period of activation as well as the moment he want the task done. The EMS then choose the most appropriate moment to execute it. 


\subsubsection{Power shiftable loads}

Power shiftable loads are loads whose power consumption can be controllable by the EMS. HVAC or water heater can be classified as power shitable loads. For this class of loads, the user specified a reference control regarding the service provided by the load (e.g. temperature in water tank must be $60^{\circ} \mathrm{C}$ between $7 \mathrm{pm}$ and $10 \mathrm{pm}$ ). The EMS then adjusts the load 's power to closely match this reference.

\subsection{Power balance}

The power balance between the components gives equation (12)(11):

$$
P_{P V}+P_{F C}+\eta_{D C D C} P_{b a t}^{-}=\frac{P_{b a t}^{+}}{\eta_{D C D C}}+\frac{P_{E L}+P_{\text {Load }}+P_{D e f}}{\eta_{D C A C}}+P_{A C o n s}
$$

Where $P_{P V}$ is the actual power delivered by solar panels, $\eta_{D C D C}$ and $\eta_{D C A C}$ are the chopper and inverter efficiencies, and $P_{\text {Acons }}$ the electrical power needed for the components to work. It contains the consumption of the controller, solenoids and others auxiliaries.

\section{Energy Management Strategies}

Energy management is a key aspect of a renewable energy system. Simply speaking, the question to answer is how to smartly use the energy produced and stored regarding the present and future situation?

\subsection{Current EMS: A myopic control}

Figure 2 shows the energy management currently implemented in RES at Parc de la Vanoise (France) and at Cirque de Mafate (Réunion island). Its general idea is described below. The batteries act like an energy buffer, storing the energy in excess and supplying energy in default for short time periods, typically 2 to 5 days. On the other hand, the hydrogen system acts like a backup system, storing energy surplus when batteries are full and returning it when production is low and batteries empty. Underlying thought is to size the PV and batteries bank regarding spring or autumns months, to store the summer surplus with the hydrogen system and to use it during winter months.

More specifically, the electrolyser becomes active when the batteries' State Of Charge $(S O C)$ reach a threshold $S O C_{E L_{O n}}$ and irradiance is greater than $\mathrm{Irr}_{t h}$. It then produces hydrogen until the $S O C$ becomes lower than $S O C_{E L_{O f f}}$ or when the hydrogen tank is full. In a similar way, the fuel cell starts when $S O C=S O C_{F C_{O n}}$ and stops when $S O C=S O C_{F C_{O f f}}$ or when the tank is empty (meaning

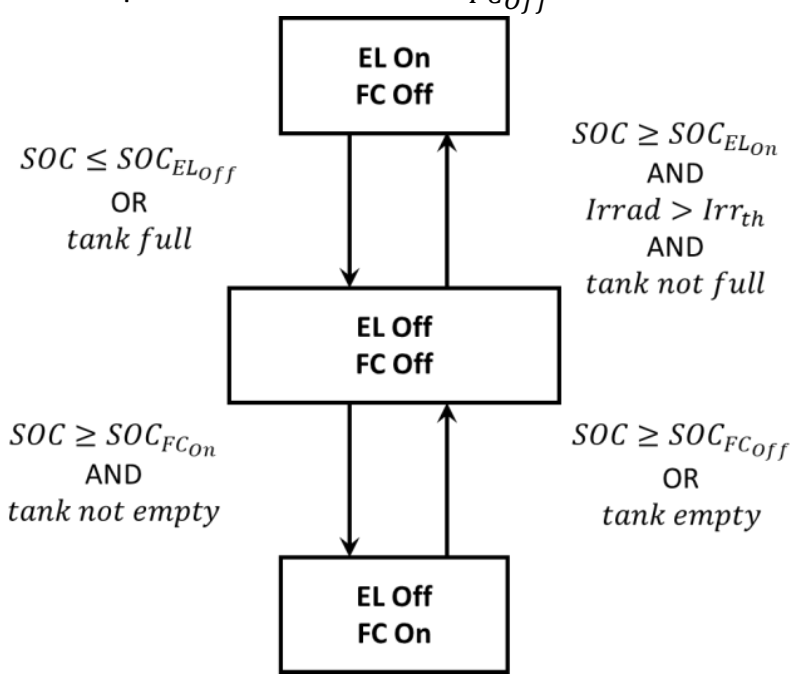

Figure 2 : Myopic EMS of the RES 
hydrogen pressure is below 0.5 bar). This type of EMS is based on real-time, measured parameters. They do not take in account what could happen in the future. For that reason, there are qualified myopic EMS [26]. A wide variety of myopic control can be implemented. Most of them are based on distinguishing when consumption is higher than production and conversely (for example see [27-29]). The described EMS however, is currently implemented in working and autonomous RES at our disposal. Consequently, it will be used to evaluate and compare performance with respect to MPC.

With myopic EMS, nothing prevents us to take a bad decision, meaning a decision that will compromise the station in the future. For example, suppose that at some point we start the electrolyser and produce hydrogen. Shortly after, the sun goes down and the solar power is not sufficient to support its consumption. Then the batteries provide the needed energy until $S O C$ reach $S O C_{E L_{O f f}}$. Suppose also that at a same time, consumption is quite high. Then batteries will quickly be empty and we will need to start the fuel cell. In this scenario, the bad timing when starting the electrolyser entails discharged batteries and consumption of hydrogen right after its production - meaning avoidable losses.

\subsection{Proposed EMS: MPC control}

In order to take into account the near future while taking a control decision, one can use a Model Predictive Control (Figure 3). This type of control uses forecasts of production and consumption to optimizes the EMS strategy over a temporal horizon $H_{c}$.

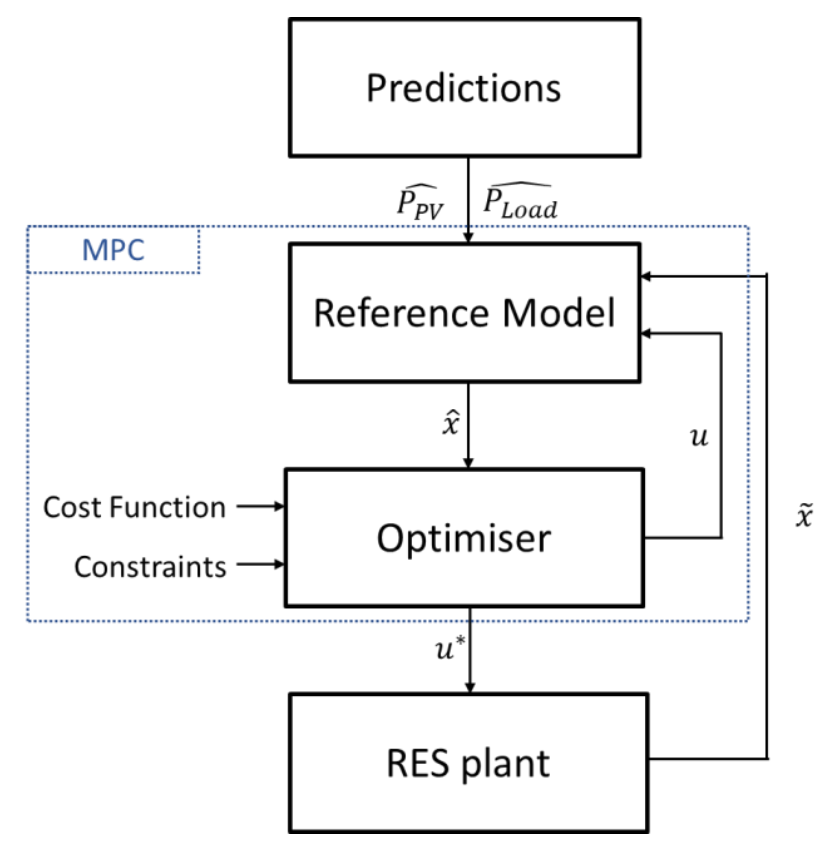

Figure 3 : Diagram of EMS with predictive control

Let's say that at time $t_{0}$ we want to determine the optimal dispatch $u^{*}$ between time $t_{0}+1$ and $t_{0}+$ $H_{c}$ regarding some objectives, $H_{c}$ being the control horizon. The performance of a particular dispatch is measured by a function $F$. A reference model $g$ is used to estimate the state $\hat{x}(t+1)$ of the RES at time $t+1$ given:

- The current or estimated state of RES at time $t: \hat{x}(t)$

- A prediction of the power production at time $t: \widehat{P_{P V}}(t)$

- A prediction of the power consumption at time $t: \widehat{P_{\text {Load }}}(t)$

- The control applied to the station: $u(t)$ 
Under these hypothesis, the optimal control is the one for which $F$ is maximal:

$$
u^{*}=\operatorname{Argmax}_{\mathrm{u}}\left(\sum_{t=t_{0}}^{H_{c}-1}\left[F\left(g\left(\hat{x}(t), u(t), \widehat{P_{P V}(t)}, \widehat{P_{\text {Load }}}(t)\right)\right)\right]\right)
$$

\subsection{Objectives}

\subsubsection{Energy availability}

In this study, three objectives will be considered. The first one means to maximise the energy available for users. This is a key issue for the control determination as it is the primary goal of installing a power production system. It will be considered by strongly penalizing power demand unmet over the optimization horizon:

$$
F_{1}\left(t_{0}\right)=\sum_{t=t_{0}+1}^{t_{0}+H}-D(t)^{2}
$$

With $D(t)$ the unmet power demand at time step $t$.

\subsubsection{Global efficiency}

The second is to reinforce the global efficiency of the RES by minimizing the power lost during the conversion process. Several types of loss are considered.

\subsubsection{Electrical conversion losses}

When converting electrical power from $A C$ to $D C$ or from $D C$ to $D C$, some losses occur in the converters. These losses are calculated by

$$
\begin{aligned}
& L_{c o n}^{t}(t)=\frac{\Delta t}{1000} {\left[\frac{\left(1-\eta_{D C A C}\right)}{\eta_{D C A C}}\left(P_{\text {Load }}(t)+P_{E L}(t)\right)\right.} \\
&\left.+\left(1-\eta_{D C D C}\right)\left(\frac{P_{b a t}^{+}(t)}{\eta_{D C D C}}+P_{b a t}^{-}(t)\right)\right]
\end{aligned}
$$

$L_{c o n}^{t}$ being the converters losses for timestep $t$. Efficiency coefficient also take into account the power needed for the converters to work (given by supplier). The $\frac{1}{1000}$ coefficient is introduced to work in kWh units.

\subsubsection{Chemical conversion losses}

Chemical losses occur batteries charges and discharges, in the electrolyser during hydrogen production, and in the fuel cell during electricity production. The losses in the batteries are computed with the batteries round trip efficiency:

$$
L_{\text {che }, \text { bat }}(t)=\frac{\Delta t}{1000} \times\left[\frac{\left(1-\sqrt{\eta_{\text {bat }}}\right)}{\sqrt{\eta_{\text {bat }}}} P_{\text {bat }}^{+}(t)+\left(1-\sqrt{\eta_{\text {bat }}}\right) P_{b a t}^{-}(t)\right]
$$

The losses in the $\mathrm{H}_{2}$ production and consumption processes are expressed as below:

$$
L_{c h e, H_{2}}(t)=\frac{\Delta t}{1000}\left[\left(P_{E L}(t)-\frac{L V H}{M} Q_{E L}(t)\right)+\left(\frac{L V H}{M} Q_{F C}(t)-P_{F C}(t)\right)\right]
$$

In (16)(12), $Q_{E L}$ is the flow of hydrogen produced by the electrolyser, $Q_{F C}$ the flow of hydrogen consumed by the fuel cell. $M$ and $L V H$ are the hydrogen molar mass and low heating value. 


\subsubsection{Availability losses}

In islanded area, energy cannot be sell or bought from the grid by definition. Hence, production must be directly consumed or stored. Otherwise it is lost. We thus introduce an energy availability loss $L_{\text {ava }}$ as follow:

$$
L_{\text {ava }}(t)=\frac{\Delta t}{1000} \max \left(P_{\text {net }}(t), 0\right)
$$

Where $P_{\text {net }}$ is difference between the theorical maximal produced power and the power actually consumed or stored:

$$
\begin{aligned}
P_{n e t}(t)=P_{P V}^{t h e o}(t)+P_{F C}(t)+\eta_{D C D C} P_{b a t}^{-}(t)-\frac{1}{\eta_{D C D C}} P_{b a t}^{+}(t) \\
-\frac{1}{\eta_{D C A C}}\left(P_{E L}(t)+P_{\text {Load }}(t)+P_{D e f}(t)\right)+P_{A C o n s}(t)
\end{aligned}
$$

\subsubsection{Global losses}

The total equation loss is expressed as below:

$$
F_{2}\left(t_{0}\right)=\sum_{t=t_{0}+1}^{t_{0}+H} L_{c o n}(t)+L_{c h e, b a t}(t)+L_{c h e, H_{2}}(t)+L_{\text {ava }}(t)
$$

\subsubsection{Components lifetime}

Last objective, but not least, is to maximize the lifetime of the energy storage components: the batteries, the electrolyser and the fuel cell. The batteries are indeed used as a buffer. Thus, they are subjects to repetitive charges and discharges that cause premature ageing and impact their lifetime. Moreover, electrolysers and fuel cells are still not mature technologies and reliability stays a critical issue [30]. Their state of health is thus supervised and taken into account. The third objective function is then given by:

$$
F_{3}\left(t_{0}\right)=\frac{1}{3} \times\left(S_{\text {OHat }}\left(t_{0}+H\right)+S O H_{E L}\left(t_{0}+H\right)+S O H_{F C}\left(t_{0}+H\right)\right)
$$

Fuel cells and electrolysers are more expensive than batteries and the technology is less mature. However, batteries are a key component to maintain the balance between production and consumption, i.e. for the system to work. For this reason, the same importance is given for $1 \%$ degradation of batteries, fuel cell or electrolyser.

It is worth to note that unlike $F_{1}$ and $F_{2}, F_{3}$ is not a cumulative function. Only the estimated states of health at the end of the optimization horizon is considered. $F_{3}$ is not path dependant.

\subsubsection{Global objective function}

The global objective function $F$ is a linear combination of sub-objectives 1, 2 and 3 :

$$
F\left(t_{0}\right)=\alpha_{1} F_{1}\left(t_{0}\right)+\alpha_{2} F_{2}\left(t_{0}\right)+\alpha_{3} F_{3}\left(t_{0}\right)
$$

The $\alpha_{i}$ coefficients enables us to adapt the magnitude of each objectives functions. We can also use them to favoured one or several objectives over the others. As the goal is to minimize unmet power demand and energetic losses, $\alpha_{1}$ and $\alpha_{2}$ are both strictly negatives while $\alpha_{3}$ is strictly positive. 


\subsection{Constraints}

The optimization problem is subjects to physical constraints described by equation (22) to (26):

$$
\begin{gathered}
S O C_{m} \leq S O C \leq S O C_{M} \\
P_{b a t, m} \leq P_{b a t} \leq P_{b a t, M} \\
\operatorname{Pre}_{m} \leq \text { Pre } \leq \operatorname{Pre}_{M} \\
Q_{E L, m} \leq Q_{E L} \leq Q_{E L, M} \\
Q_{F C, m} \leq Q_{F C} \leq Q_{F C, M}
\end{gathered}
$$

Subscripts $m$ and $M$ stand for minimal and maximal respectively. Pre is the $H_{2}$ pressure inside the tank.

\section{Simulation and Results}

\subsection{Simulation}

In order to evaluate the performance improvement brought by MPC, simulations of an RES station with a myopic control and a model predictive control have been simulated. Results are shown and compared in next sections. Irradiance, temperature and load power data come from measurements done at the mountain refuge Col du Palet in Parc de la Vanoise, France between January 2017 and December 2017. Missing data have been manually reconstructed using similar days data. Irradiance and load power for a typical week in august are shown in Figure 4. As can be observed, consumption peaks can occur so the energy management must provide sufficient power reserve to supply them. Moreover, production alone is clearly not sufficient to meet the desire demand, particularly early in the morning, late at in evening and at night. This justify the need of storage, no matter how many solar panels are installed. 


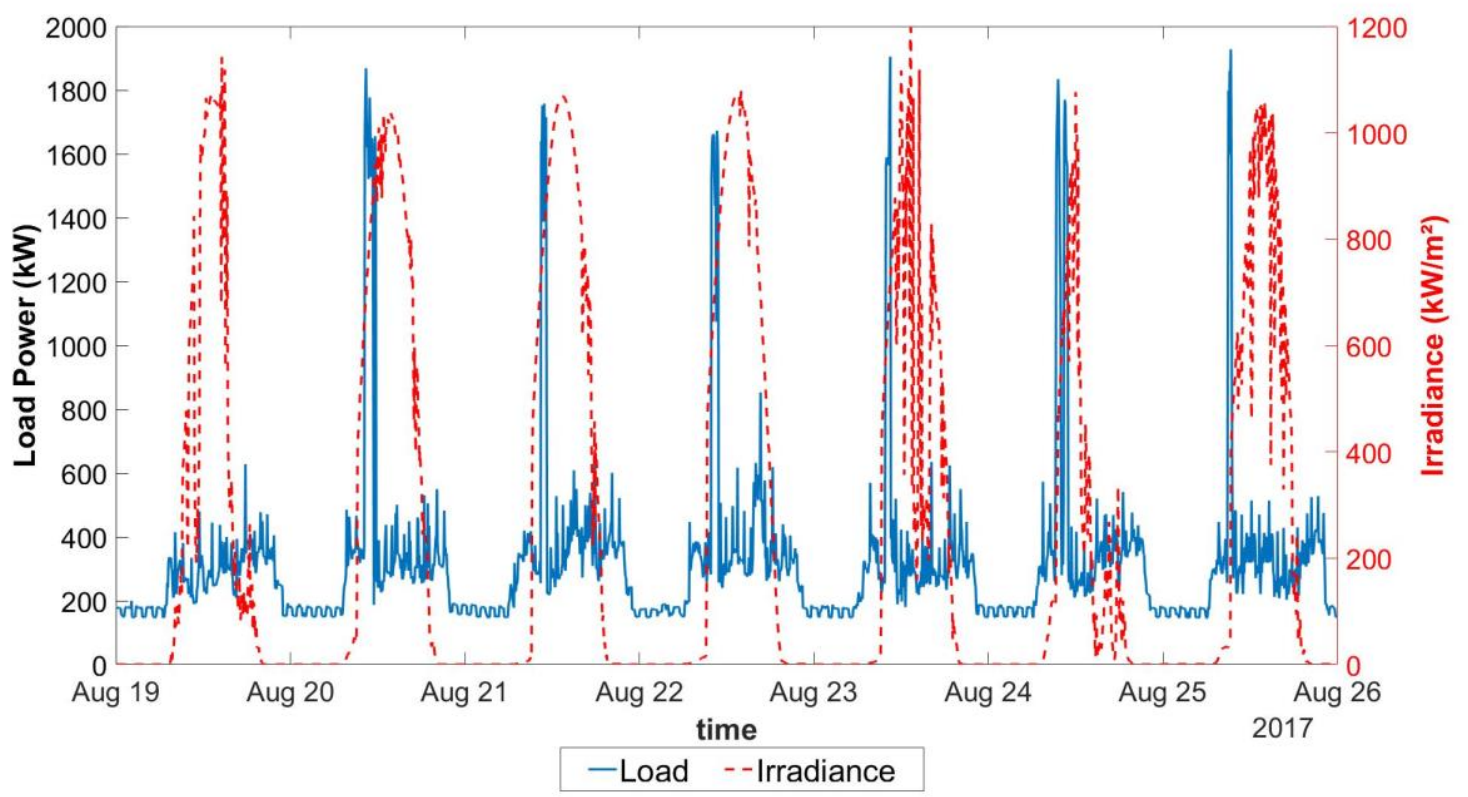

Figure 4 : Typical days in august for load power $(\mathrm{W})$ and Irradiance $\left(\mathrm{W} / \mathrm{m}^{2}\right)$

The simulated RES is composed of 2 branches of 5 PV panels with a total installed power of $3.2 \mathrm{KWc}$. The batteries bank is composed of $4 \mathrm{Saft} 48 \mathrm{~V}$ Li-lon batteries if a nominal capacity of 77Ah [31]. The electrolyser is a 2.5KW Acta ELS500 [32] able to deliver a 500L/h pressurised hydrogen flow. The fuel cell is an E-2500 PEM fuel cell from PlugPower [33] with a nominal power of 2.5KW. The hydrogen tank can store $1100 \mathrm{~L}$ of gaseous hydrogen under 30 bars.

This sizing does not correspond to the one installed at the Parc de la Vanoise and is purposely undersized. Indeed, as the station was designed to meet the load with the myopic control described in section 4, simulations with actual sizing return no default time. It is then impossible to quantify the performance gain for this objective. As reducing the default time is our number one priority, we need a design for which both control strategies fail to meet the load for the whole simulation. For the same reason, the hydrogen tank is supposed to be half empty at the beginning of simulations.

Table 1 : Objectives ponderation used for MPC control

\begin{tabular}{rrr}
$\alpha_{1}$ & $\alpha_{2}$ & $\alpha_{3}$ \\
\hline 5000 & -1 & 30000 \\
\hline
\end{tabular}

For the sake of simplicity, deferrable loads are not taken into account. Then the control vector $u$ is reduce to the electrolyser and fuel cell activation. The temporal horizon considered is $12 \mathrm{~h}$-ahead with a 30-min time step. Ponderation used to order objectives is given by Table 1. It has been obtained iteratively following a manual Trial and Error procedure. At the first step, ponderation was set to $\alpha_{1}=$ $\alpha_{2}=-1$ and $\alpha_{3}=1$ and a simulation has been performed. This led the final value of objective functions $F_{1}, F_{2}$ and $F_{3}$ to be different by several orders of magnitude, $F_{2}$ being much greater than $F_{1}$ and $F_{3}$. Hence, with this ponderation the MPC strongly favour the reduction of energetic losses over the over two objectives. To fix this issue, we set $\alpha_{1}=\alpha_{2} \frac{F_{2}(0)-F_{2}(\text { end })}{F_{1}(0)-F_{1}(\text { end })}$ and $\alpha_{3}=\alpha_{2} \frac{F_{2}(0)-F_{2}(\text { end })}{F_{3}(0)-F_{3}(\text { end })}$ and repeat the process until each objectives function worth nearly equally in the global objective function $F$. Finally, the weights are adjusted by doubling $\alpha_{1}$ and by multiplying $\alpha_{3}$ by $2 / 3$ to strongly favour objectives 1 over 2 and 3 and shortly favour 2 over 3 . The optimization problem is solved using Branch 
and Bound algorithm and a rolling horizon technique is employed. As the goal of this study is to quantify the maximal improvement that could be brought by MPC, the load and production forecasts are supposed to be perfectly known. Similarly, the reference model is assumed to perfectly estimate the station behaviour. The results are exposed in next section.

\subsection{Results and Discussion}

\subsubsection{Results}

To better understand how MPC affects the station, Figure 5 and Figure 6 give the station behaviour for two days with different conditions as example. In order not to overcharge this paper, a focus is given on energetic losses only.

August $11^{\text {th }}$ was a cloudy day, with low consumption but with a peak between 9:00 and 10:00 AM. Batteries are mid-charged at the beginning of the day and are the only energy supplier during the night. They are about to reach their lower threshold when the peak starts. MPC then turns the fuel cell on, so it can supply peak demand and to recharge the batteries a little. When the peak is over, the solar power is sufficient to provide the demand until 7:00 PM. At the end of the day, MPC anticipate that batteries are not sufficiently charged to cover the energy needs during the next night. It then turns on the fuel cell again, but only enough to allow the batteries to get it through the night. Finally, MPC anticipate the next day will be a low consumption day, sunny enough to fully recharge the batterie without activating the fuel cell. This is why it does not turn it on even if batteries are close to the minimal threshold at dawn. This example shows that MPC use only the correct amount of hydrogen needed and turns on the fuel cell at the most appropriate time step (during the consumption peak). In a similar situation, a myopic control would have turn on the batteries until $S O C$ reaches $S O C_{F C_{O f f}}$ (70\% in this simulation). This would have led to an excessive consumption of hydrogen without choosing the appropriate time to do it.

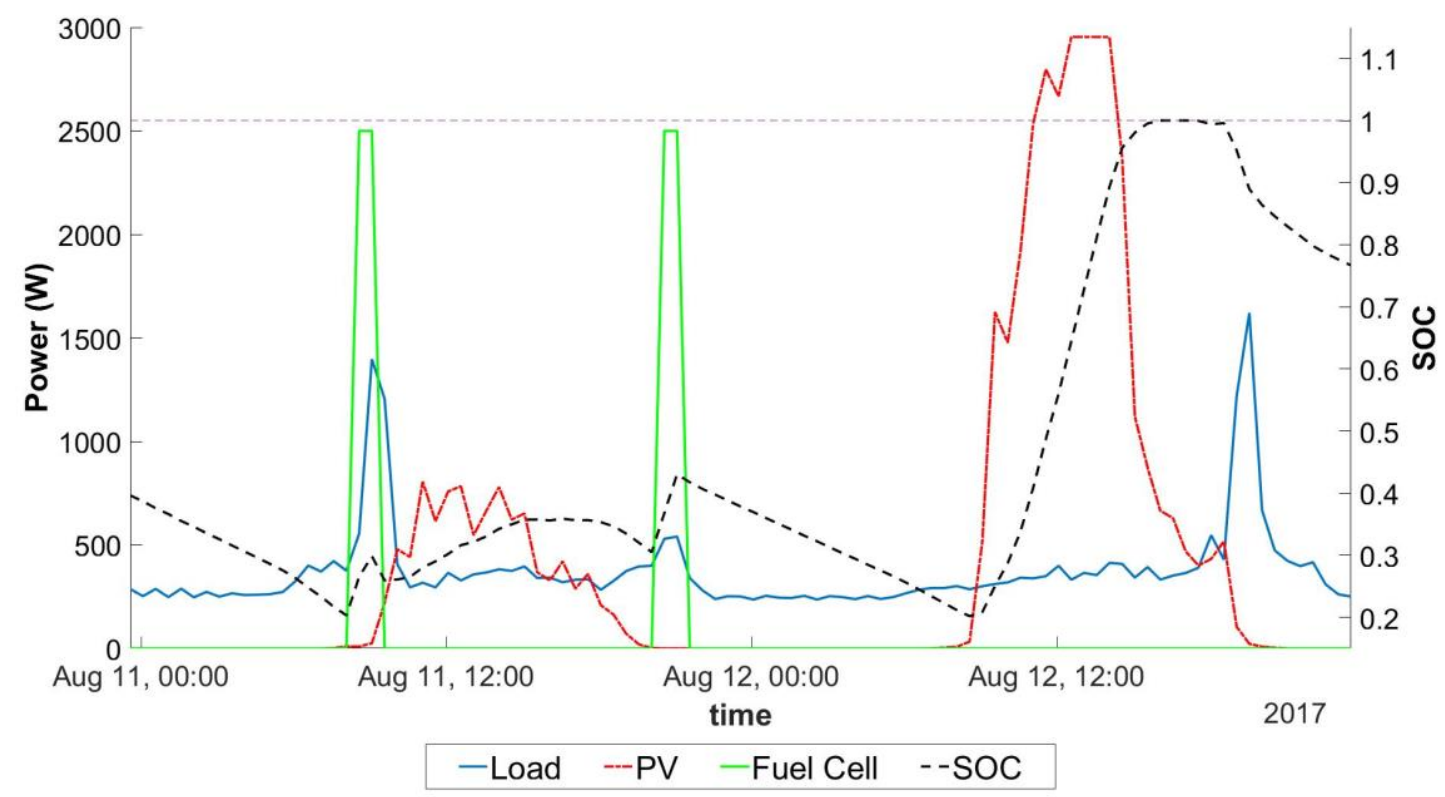

Figure 5: PV, Load, Fuel cell powers and batteries SOC during the $11^{\text {th }}$ and $12^{\text {th }}$ of August

On the over hand, October the 30th is a sunny, low consumption day and present a great opportunity to produce hydrogen. Here a myopic control would have start recharging the batteries first, and only when $S O C$ reaches $S O C_{E L_{O n}}$ the electrolyser would have been switched on. However, solar power is 
rarely sufficient to supply the electrolyser by itself. Hence batteries need to be use to cover the difference. At the end of the day, batteries would have been charged by solar power, and then partly discharged to supply the electrolyser. This process leads to avoidable energy losses.

MPC however decides to switch the electrolyser on before charging the batteries, when solar power is maximal. Doing this, the energy needed from the batteries is minimised. It then switches the electrolyser off in time for the batteries to be fully charged at sundown. Here again, by choosing the best time to activate the electrolyser, MPC allows to minimise the energetic losses.

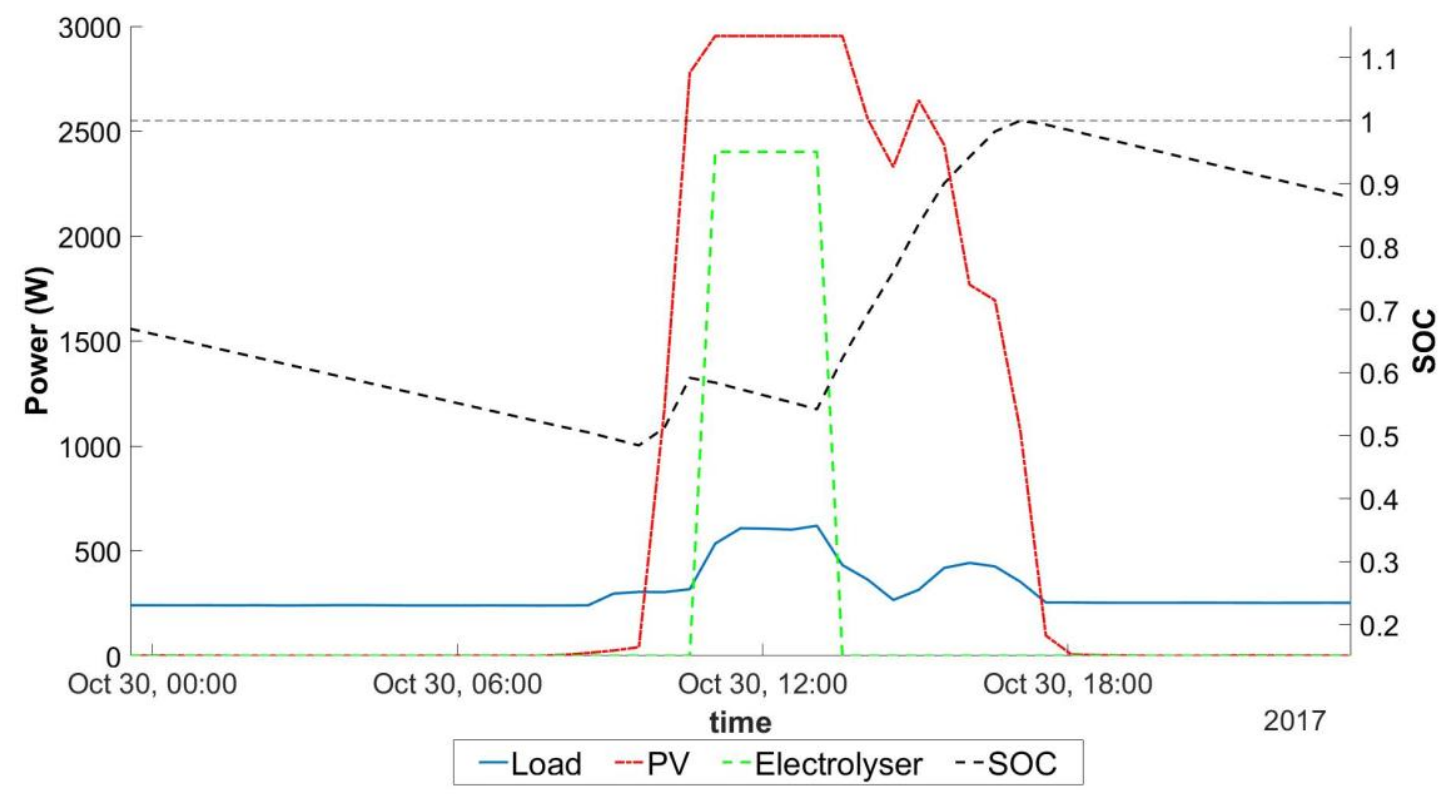

Figure 6: PV, Load, Electrolyser powers and batteries SOC during the $30^{\text {th }}$ of October

\subsubsection{Energy availability}

Table 2 compares myopic and MPC control in term of load supplied (objective 1). The EMS is considered in default at a specific time step if it cannot provide enough power to meet the demand. It can be seen that MPC allows significant improvement, with only 150 default time steps against 629 for myopic control. This corresponds to an improvement of $76 \%$.

\begin{tabular}{lcc} 
Table 2: Loss of Load comparison between Myopic control and MPC \\
\hline & Myopic & MPC \\
\hline Number of default time-step & 629 & 150 \\
Total default time (h) & 314.5 & 75 \\
Total of not supplied demand (KWh) & 80 & 24.3 \\
\hline
\end{tabular}

Moreover, we can see in Figure 7 that batteries are better charged with MPC. In fact, batteries are nearly fully charged (SOC comprised between 0.95 and 1) nearly $20 \%$ of the year and SOC is above 0.7 during $72 \%$ of the year. In contrast, with a myopic control the batteries are nearly fully charged only $13 \%$ of the year and their SOC is above 0.7 for only $49 \%$ of simulation time. 


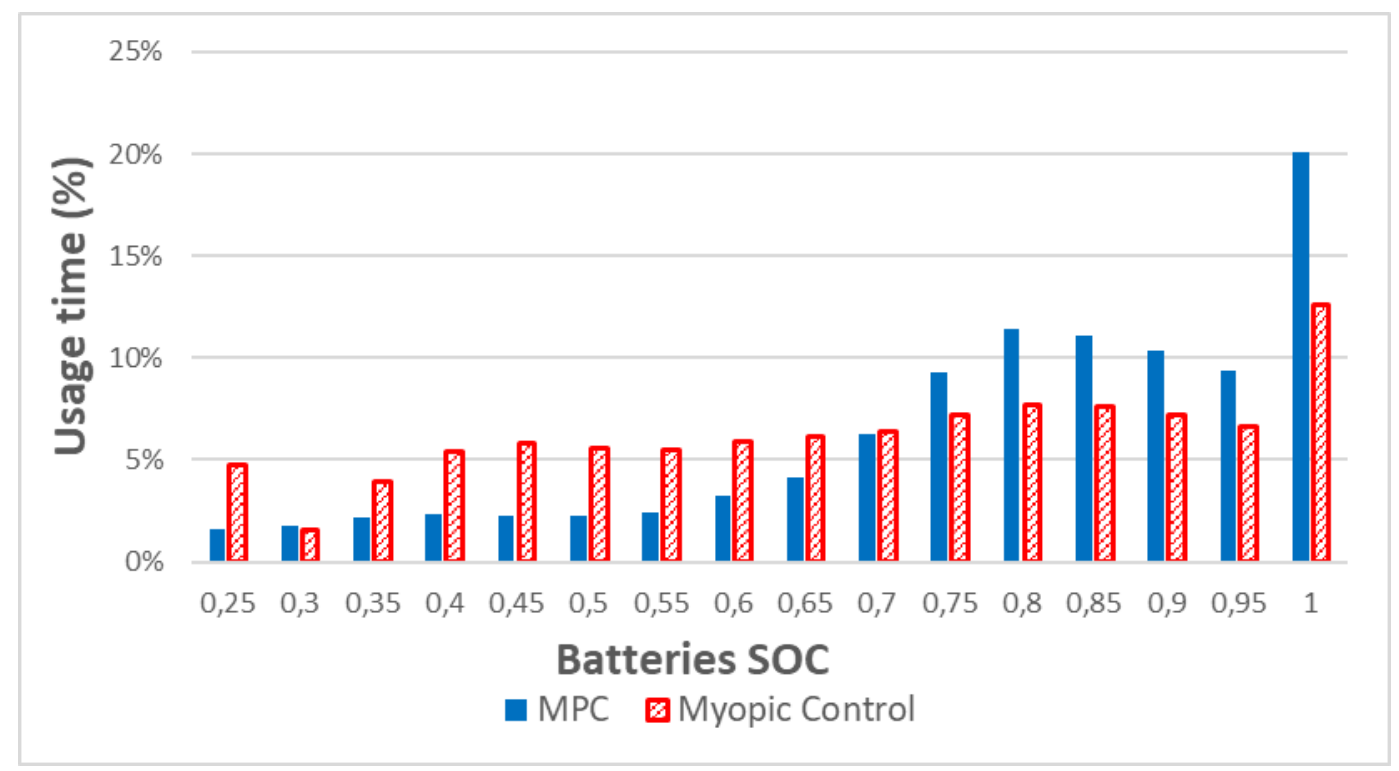

Figure 7 : Repartition of batteries SOC in term of time percentage with a MPC control (blue) and a myopic control (red)

Likewise, Figure 8 shows the quantity of hydrogen stored in the tank throughout the year. Once again, improvement brought by MPC is obvious. While with a myopic control the average fill rate of the hydrogen is $22 \%$, MPC achieve a fill rate of $82 \%$. It is worth noticing that MPC get this result despite producing less hydrogen that the myopic control over the simulated year. Simulations show indeed that the electrolyser produce $9.6 \mathrm{Kg}$ of hydrogen with MPC and $15.8 \mathrm{Kg}$ with the myopic control. This shows that a better management of hydrogen production can significantly improve the storage performance.

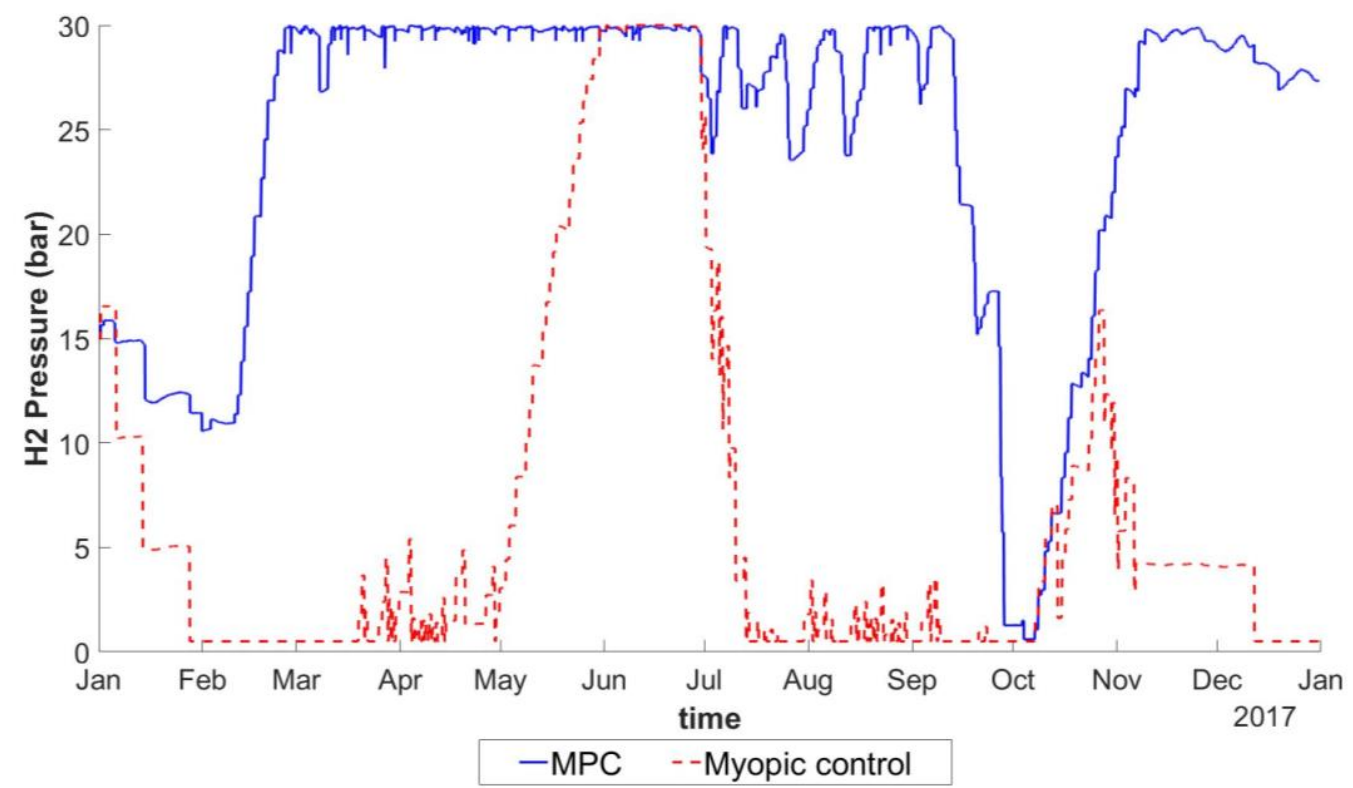

Figure $8: H_{2}$ stocked in tank through the year

\subsubsection{Power Losses}

Figure 9 gives the cumulative losses for myopic control (dashed red line) and MPC (blue line).

Up-left graph represents the chemical losses during the electrochemical process. Between March and April, chemical losses are higher with MPC. But at the end of the year MPC improves chemical losses 
by $38 \%$. As the round-trip efficiency of Li-Ion batteries is close to 1 (we took $\eta_{b a t}=0.9$ in this study), the production and consumption of hydrogen constitute the main contribution to these losses. As said in previous section, myopic control tends to overproduce hydrogen. This is also true for hydrogen consumption (17.2kg consumed with myopic control against $8.4 \mathrm{~kg}$ with MPC). This leads to superior chemical losses with myopic control. The reason why chemical losses with MPC are greater between March and April is the tank filling happening in February.

In up-right graph, one can see the electrical losses occurring in the converters. Here again, MPC get the best results. Nevertheless, this improvement is limited to $11 \%$, mostly because of the high efficiency of the converter, above 0.9. The gap can be explained by lower battery power, partly compensate by greater demand response (meaning greater use of the inverter).

The down-left graph gives the availability losses. Here MPC underperform myopic control by $29 \%$. Two reasons explain this result. The first reason is that despite a better energy management, the RES is still undersized with MPC. Storage capacity are particularly limited. Then between March and July excess of solar power can no longer be stored, the tank being full. Second, between July and October myopic control is in very short energy supply. So, every last joule generated is ever store or used, leading to a long available losses stabilisation. Both reasons can be resolve by a better sizing of the station.

At last, total losses are shown in the down-right graph. As one can see, MPC outperform myopic control with a global improvement of $1 \%$. This poor improvement is explained by the fact that the good performances obtained for chemical and electrical losses are counterbalanced by the bad performance for availability losses. As MPC is supposed to perform better under realistic sizing, the overall improvement is expected to be higher.
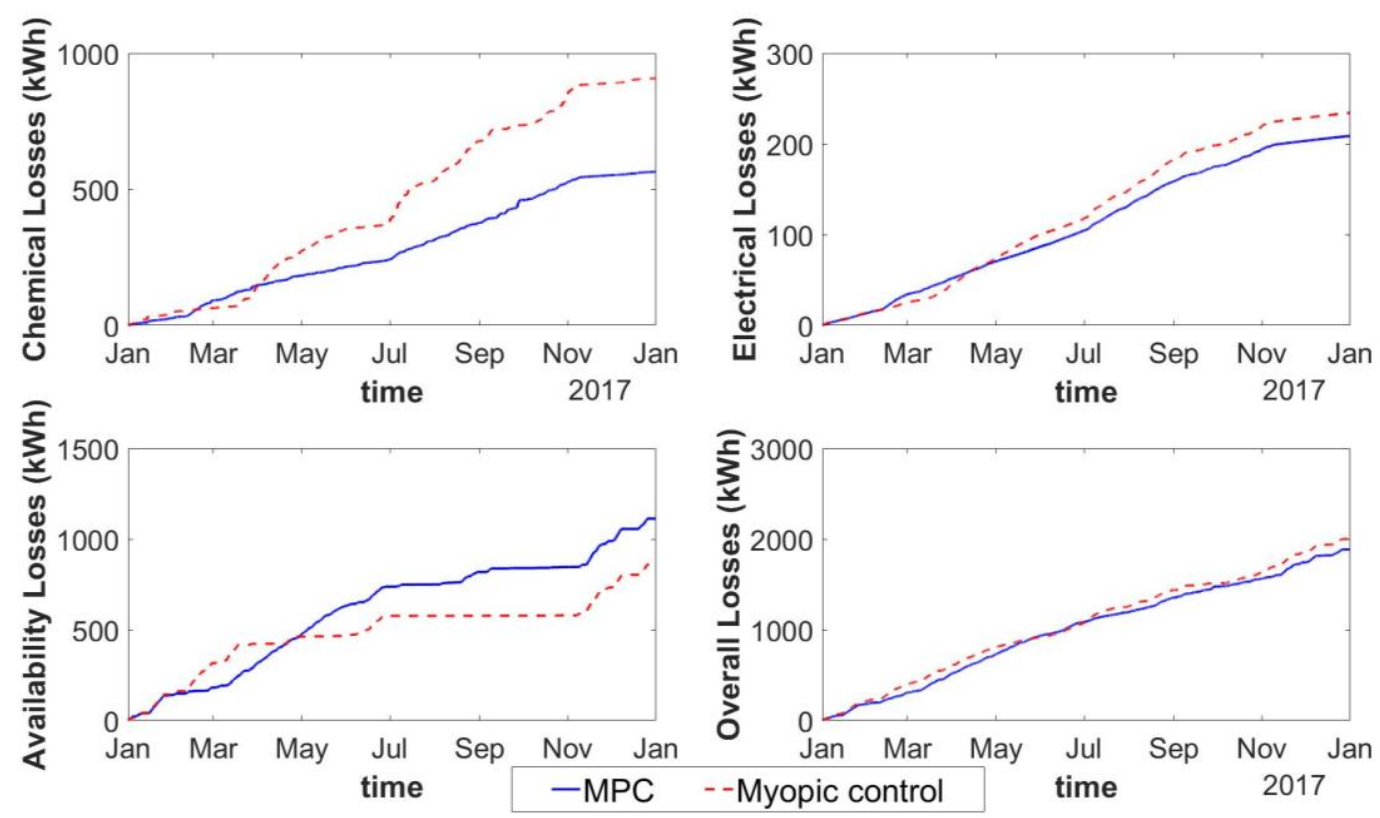

Figure 9 : Power losses for MPC and Myopic control

\subsubsection{Component lifetime}



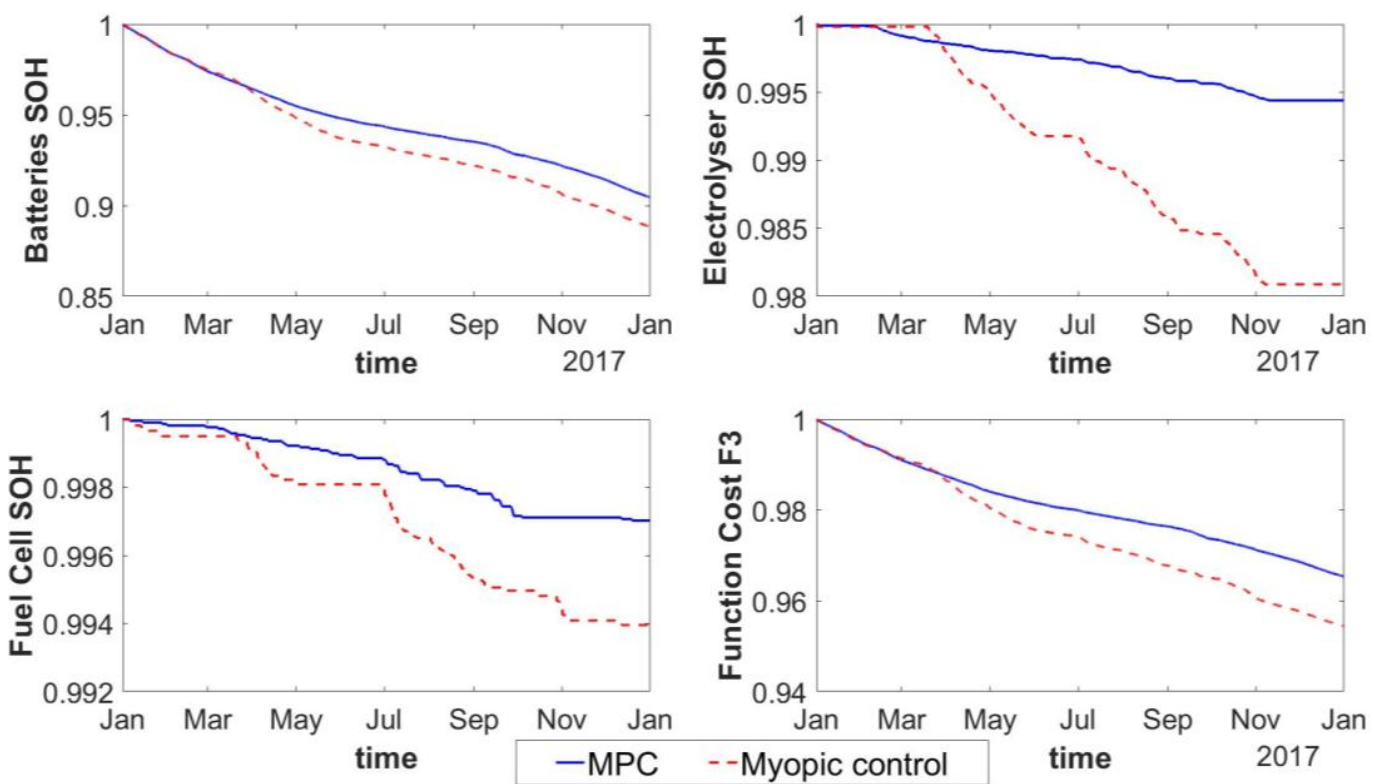

Figure 10: State of health of batteries, electrolyser, fuel cell and overall

Figure 10 presents the state of health evolution of batteries (up-left), electrolyser (up-right), fuel cell (down-left) and the $F_{3}$ objective function.

Both controls tend to impact the batteries more than the fuel cell and the electrolyser. $\mathrm{SOH}_{\text {bat }}$ is indeed 0.90 and 0.89 at the end of simulation for MPC and myopic control respectively. On the other hand, $S O H_{E L}$ ends at 0.99 and 0.98 while $S O H_{F C}$ is around 1 for MPC and 0.99 for myopic control. In every case, MPC mitigate the components degradation by approximately $1 \%$. When extrapolated, this result suggest that batteries need to be replaced every 10.5 years with MPC and every 9 years with myopic control. This could be very welcomed in remote area.

However, the fuel cell and electrolyser durability, even if better with MPC, has to be put in perspective with the excellent performance obtained by the myopic control on this matter. This is mostly due to the 30 min time-step taken in the simulation. Indeed, On and Off switches are the more impacting actions on durability in normal operating conditions. As a high time-step inherently limits the number of possible activations - deactivations, a good durability was predictable.

To better see the relevance of MPC on the fuel cell and electrolyser degradations, Figure 11 shows the degradations of batteries, fuel cell and electrolyser for a 10-min time-step for a myopic control and MPC with several ponderations $\alpha_{3}$. A temporal horizon of $6 \mathrm{~h}$ is adopted for the computation time to be compatible with a real-time control. Here, as expected, the number of activations and deactivations is higher, making the improvement brought by MPC more pronounced. This is particularly true for the electrolyser. $\mathrm{SOH}_{E L}$ is indeed equal to 0.95 with myopic control and 0.99 with $\mathrm{MPC}\left(\alpha_{3}=30000\right)$, meaning an improvement of $20 \%$. Another interesting result is the fact that ageing is mitigate for electrolyser and batteries with MPC, even if the durability is not considered $\left(\alpha_{3}=0\right)$. This is explained by less and shorter discharges for the batteries and a shorter time of use for electrolyser. This is however not true for the fuel cell, as MPC turns it on often and for very short period of time to cover demands peaks. However, a higher ponderation does not significantly increase the durability, but degrade the performances in the other objectives $\left(\alpha_{3}=60000\right)$. 

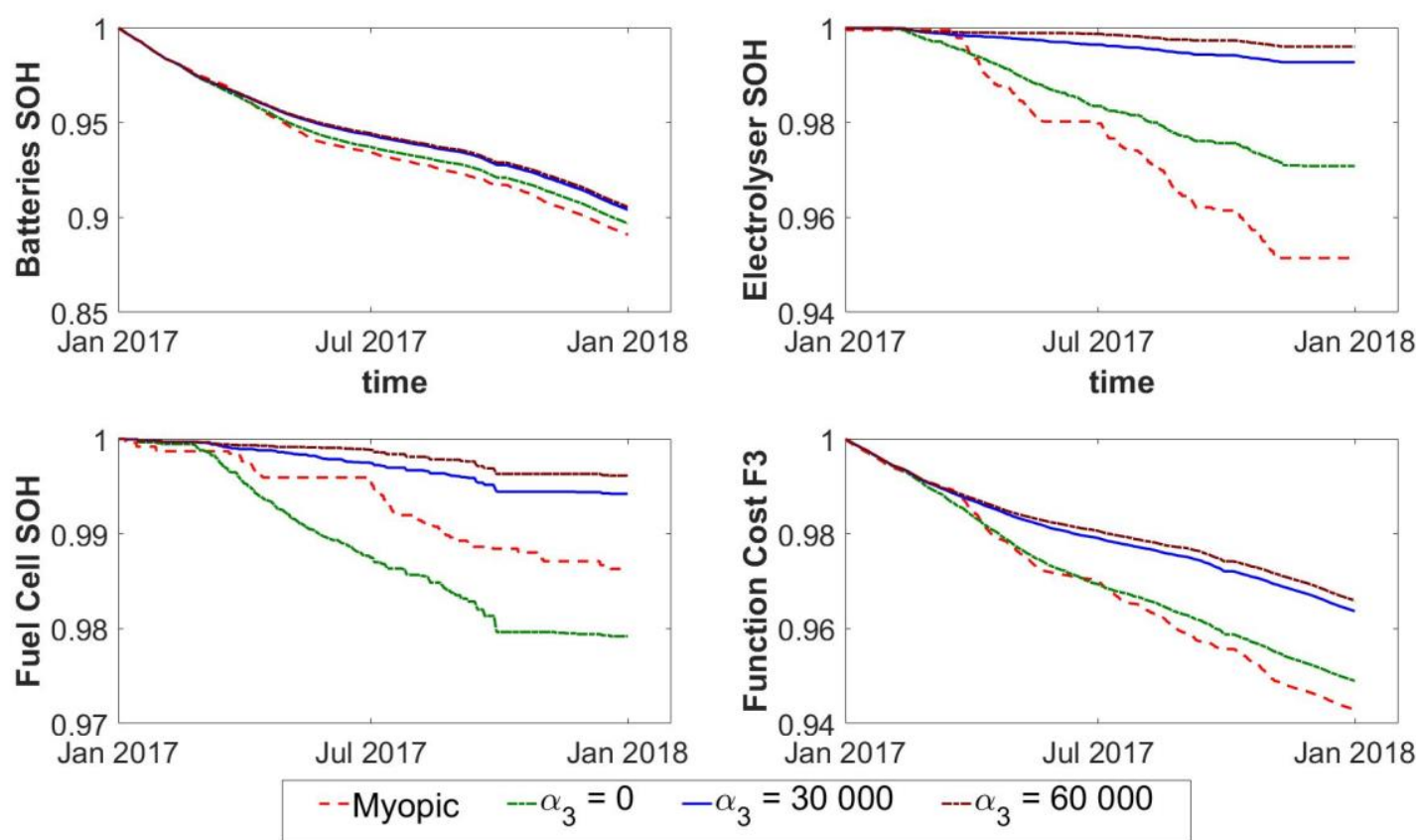

Figure 11 : State of health of batteries (up left), electrolyser (up right), fuel cell (down left) and overall (down right) MPC considering or not ageing process in MPC and Myopic Control

At the end, the inclusion of fuel cell and electrolyser degradation in MPC control will depend on the time-step considered. In theory, a lower time-step is preferable as it allows more freedom. But in practise, it will be limited by the number of equipment to control, and by the quality of the forecasts models.

\section{Conclusion}

This study aims to give an evaluation of performance improvement of a RES controlled by MPC. Advantage of MPC is to control the station's components using production and consumption forecasts. Doing this, decisions are taken without compromising the near future. Results shows that MPC can achieve substantial improvements and savings. The - undersized - station is indeed in default for $75 \mathrm{~h}$ against $314.5 \mathrm{~h}$ with a myopic control. In the meantime, chemical losses have been reduced by $38 \%$ and electrical losses by $11 \%$. Moreover, if MPC seems relevant to reduce the premature ageing of batteries, its impact on fuel cell and electrolyser depends greatly on the time-step of the control. The priority between objective is another factor as well. This raise the question of how to optimally tune the ponderation weight. Ponderation shown Table 1 have been obtained with a Trial and Error methods but more sophisticated Pareto-based techniques can be implemented.

Besides, it is important to notice that these improvements must be seen as an optimal target. In other words, improvements brought by MPC on the studied RES will never be better than what we obtained above. In practise, production and consumption forecasts are strong limitations to reach these improvements. The reference model used in MPC is another one as well (not planned process can lead to significant deviation with actual behaviour). Future works must be done to integrate those restrictions in the energy management. Eventually, the goal of this work and future work is to develop a real-time control which performance are the closest as possible to the ones above. 


\section{Acknowledgments}

This work is supported by the National Agency of Research and Technology of France through the program Cifre under grant 2016/0950.

Authors also address their warms thanks to the Parc de la Vanoise for the consumption and weather data provided. 


\section{Bibliography}

[1] Valverde L, Bordons C, Rosa F. Power management using model predictive control in a hydrogenbased microgrid. IECON 2012-38th Annu. Conf. IEEE Ind. Electron. Soc., IEEE; 2012, p. 5669-5676.

[2] Cau G, Cocco D, Petrollese M, Knudsen Kær S, Milan C. Energy management strategy based on short-term generation scheduling for a renewable microgrid using a hydrogen storage system. Energy Convers Manag 2014;87:820-31. doi:10.1016/j.enconman.2014.07.078.

[3] Serna Á, Yahyaoui I, Normey-Rico JE, de Prada C, Tadeo F. Predictive control for hydrogen production by electrolysis in an offshore platform using renewable energies. Int J Hydrog Energy 2016. doi:10.1016/j.ijhydene.2016.11.077.

[4] Konstantinopoulos SA, Anastasiadis AG, Vokas GA, Kondylis GP, Polyzakis A. Optimal management of hydrogen storage in stochastic smart microgrid operation. Int J Hydrog Energy 2017. doi:10.1016/j.ijhydene.2017.06.116.

[5] Bornapour M, Hooshmand R-A, Khodabakhshian A, Parastegari M. Optimal stochastic coordinated scheduling of proton exchange membrane fuel cell-combined heat and power, wind and photovoltaic units in micro grids considering hydrogen storage. Appl Energy 2017;202:308-22. doi:10.1016/j.apenergy.2017.05.133.

[6] Torreglosa JP, García P, Fernández LM, Jurado F. Energy dispatching based on predictive controller of an off-grid wind turbine/photovoltaic/hydrogen/battery hybrid system. Renew Energy 2015;74:326-36. doi:10.1016/j.renene.2014.08.010.

[7] M. Trifkovic, M. Sheikhzadeh, K. Nigim, P. Daoutidis. Modeling and Control of a Renewable Hybrid Energy System With Hydrogen Storage. IEEE Trans Control Syst Technol 2014;22:169-79. doi:10.1109/TCST.2013.2248156.

[8] Nease J, Adams TA. Application of rolling horizon optimization to an integrated solid-oxide fuel cell and compressed air energy storage plant for zero-emissions peaking power under uncertainty. Comput Chem Eng 2014;68:203-19. doi:10.1016/j.compchemeng.2014.06.001.

[9] Valverde L, Rosa F, Bordons C, Guerra J. Energy Management Strategies in hydrogen Smart-Grids: A laboratory experience. Int J Hydrog Energy 2016;41:13715-25. doi:10.1016/j.ijhydene.2016.05.279.

[10]J. Salazar, L. Valverde, F. Tadeo. Predictive control of a renewable energy microgrid with operational cost optimization. IECON 2013 - 39th Annu. Conf. IEEE Ind. Electron. Soc., 2013, p. 7950-5. doi:10.1109/IECON.2013.6700461.

[11] Salazar Salas JC. MPC-BASED ENERGY MANAGEMENT SYSTEM FOR HYBRID RENEWABLE ENERGIES. 2015.

[12] Bornapour M, Hooshmand R-A, Parastegari M. An Efficient Scenario-Based Stochastic Programming method for Optimal Scheduling of CHP-PEMFC, WT, PV and Hydrogen Storage Units in Micro Grids. Renew Energy 2018. doi:10.1016/j.renene.2018.06.113.

[13] Brka A, Al-Abdeli YM, Kothapalli G. Predictive power management strategies for stand-alone hydrogen systems: Operational impact. Int J Hydrog Energy 2016;41:6685-98. doi:10.1016/j.ijhydene.2016.03.085.

[14] Dufo-López R, Fernández-Jiménez LA, Ramírez-Rosado IJ, Artal-Sevil JS, Domínguez-Navarro JA, Bernal-Agustín JL. Daily operation optimisation of hybrid stand-alone system by model predictive control considering ageing model. Energy Convers Manag 2017;134:167-77. doi:10.1016/j.enconman.2016.12.036.

[15] Bruni G, Cordiner S, Mulone V, Rocco V, Spagnolo F. A study on the energy management in domestic micro-grids based on Model Predictive Control strategies. Energy Convers Manag 2015;102:50-8. doi:10.1016/j.enconman.2015.01.067.

[16] Luo XJ, Fong KF. Development of multi-supply-multi-demand control strategy for combined cooling, heating and power system primed with solid oxide fuel cell-gas turbine. Energy Convers Manag 2017;154:538-61. doi:10.1016/j.enconman.2017.11.032. 
[17] Vergara-Dietrich JD, Morato MM, Mendes PRC, Cani AA, Normey-Rico JE, Bordons C. Advanced chance-constrained predictive control for the efficient energy management of renewable power systems. J Process Control 2017. doi:10.1016/j.jprocont.2017.11.003.

[18] Abad AV, Staffell I, Dodds PE, Scamman DP, Mac Dowell N, Ward K, et al. The role of Hydrogen and Fuel Cells in Future Energy Systems. H2FC; 2017.

[19] Luque A, Hedgedus S. Handbook of Photovoltaic Science and Engineering. 2nd ed. 2011.

[20] Skoplaki E, Palyvos JA. Operating temperature of photovoltaic modules: A survey of pertinent correlations. Renew Energy 2009;34:23-9. doi:10.1016/j.renene.2008.04.009.

[21] Nuhic A, Terzimehic T, Soczka-Guth T, Buchholz M, Dietmayer K. Health diagnosis and remaining useful life prognostics of lithium-ion batteries using data-driven methods. J Power Sources 2013;239:680-8. doi:10.1016/j.jpowsour.2012.11.146.

[22] Wang J, Liu P, Hicks-Garner J, Sherman E, Soukiazian S, Verbrugge M, et al. Cycle-life model for graphite-LiFePO4 cells. J Power Sources 2011;196:3942-8. doi:10.1016/j.jpowsour.2010.11.134.

[23] Wang J, Purewal J, Liu P, Hicks-Garner J, Soukazian S, Sherman E, et al. Degradation of lithium ion batteries employing graphite negatives and nickel-cobalt-manganese oxide + spinel manganese oxide positives: Part 1, aging mechanisms and life estimation. J Power Sources 2014;269:937-48. doi:10.1016/j.jpowsour.2014.07.030.

[24] Barbir F. PEM Fuel Cells - Theory and Practice. 2nd ed. Elsevier; 2013.

[25] Wu J, Yuan XZ, Martin JJ, Wang H, Zhang J, Shen J, et al. A review of PEM fuel cell durability: Degradation mechanisms and mitigation strategies. J Power Sources 2008;184:104-19. doi:10.1016/j.jpowsour.2008.06.006.

[26] Powell WB. Clearing the Jungle of Stochastic Optimization. In: Newman AM, Leung J, Smith JC, Greenberg HJ, editors. Bridg. Data Decis., INFORMS; 2014, p. 109-37. doi:10.1287/educ.2014.0128.

[27] Dufo-López R, Bernal-Agustín JL, Contreras J. Optimization of control strategies for stand-alone renewable energy systems with hydrogen storage. Renew Energy 2007;32:1102-26. doi:10.1016/j.renene.2006.04.013.

[28] Caisheng Wang, Nehrir MH. Power Management of a Stand-Alone Wind/Photovoltaic/Fuel Cell Energy System. IEEE Trans Energy Convers 2008;23:957-67. doi:10.1109/TEC.2007.914200.

[29] Nasri S, Ben Slama S, Yahyaoui I, Zafar B, Cherif A. Autonomous hybrid system and coordinated intelligent management approach in power system operation and control using hydrogen storage. Int J Hydrog Energy 2017. doi:10.1016/j.ijhydene.2017.01.098.

[30] Jouin M, Bressel M, Morando S, Gouriveau R, Hissel D, Péra M-C, et al. Estimating the end-of-life of PEM fuel cells: Guidelines and metrics. Appl Energy 2016;177:87-97. doi:10.1016/j.apenergy.2016.05.076.

[31] SAFT. Evolion Li-ion battery - Technical Manual 2015.

[32] Acta. DataSheet ELS250 - 500 - 1000 n.d.

[33] PlugPower. E-Series Fuel Cell System - Operator's Manual.pdf 2015. 